\title{
A visão das empresas sobre as relações entre universidade e empresa no Brasil: uma análise baseada nas categorias de intensidade tecnológica ${ }^{1}$
}

Marcelo Pinho ${ }^{2}$

Resumo: Este artigo sintetiza alguns dos resultados de um amplo levantamento realizado junto a empresas brasileiras sobre as relações que elas mantêm com universidades e institutos públicos de pesquisa. Dos vários recortes possíveis, privilegia-se aqui a discriminação dos dados por categorias de empresas classificadas com base na intensidade tecnológica. Um instrumento de análise importante é a comparação com os resultados de um survey semelhante realizado nos EUA (Cohen et al., 2002), o qual precedeu e inspirou o levantamento feito no Brasil. Entre as achados da pesquisa, destaca-se o fato de as empresas brasileiras interrogadas atribuírem maior importância às universidades como fonte de informação para suas atividades de desenvolvimento tecnológico do que suas congêneres norte-americanas. A seção final do artigo, além de resumir outras conclusões relevantes, procura apresentar uma interpretação para o resultado mais importante, que foge bastante ao senso comum sobre o tema.

Palavras-chave: Interação universidade-empresa; Inovação em países em desenvolvimento; Sistemas nacionais de inovação.

1 A elaboração deste artigo não teria sido possível sem um grande esforço de levantamento de informações realizado por uma equipe de dezenas de pesquisadores de vários estados do Brasil. Como a lista de envolvidos nesse esforço seria muito longa e, não obstante, provavelmente incompleta, o autor dirige seus agradecimentos aos coordenadores desse grupo, Wilson Suzigan e Eduardo da Motta e Albuquerque. O autor não pode, porém, deixar de consignar um agradecimento particular a Hannah Mayumi Morikawa, estudante de engenharia de produção, por sua assistência na sistematização e tabulação dos dados apresentados e analisados neste artigo. Agradece também os valiosos comentários e sugestões de Ana Lúcia Vitale Torkomian e Vanessa Parreiras de Oliveira. Nada disso, naturalmente, implica compartilhar a responsabilidade por eventuais erros e omissões. Cabe, por fim, registrar o apoio financeiro à pesquisa prestado pelo CNPq (Processos n ${ }^{0}$ 478.994/2006-o e 478.918/2009-7) e pela Fapesp (Processo $n^{0}$ 06/58878-8).

2 Professor do Departamento de Engenharia de Produção da Universidade Federal de São Carlos - UFSCar. E-mail: mpinho@power.ufscar.br. 


\title{
The vision of firms about university-industry links in Brazil: an analysis based on the categories of technological intensity
}

\begin{abstract}
This paper reports results from a survey with Brazilian firms about university-industry links. It relies on data collected through a questionnaire applied to 324 firms that was subsequently broke down in ten different categories according to sectoral technology intensity. Analysis benefitted a lot from comparison with a previous and quite similar survey carried out in USA (Cohen et al, 2002). Among the findings of the research, there is one that was definitely unexpected: the surveyed Brazilian firms attributed a greater importance to universities as sources of information than American firms did. Besides summarizing other relevant results, the concluding section of the paper proposes an explanation for its most surprising finding.
\end{abstract}

Keywords: University-industry links; Innovation in developing countries; National innovation systems.

JEL: O3O.

Introdução

Embora a literatura sobre a inovação tecnológica tenha se afastado da visão de que o desenvolvimento tecnológico é um mero resultado da aplicação prática das descobertas científicas, o reconhecimento da existência de relações mais complexas entre ciência e tecnologia nem de longe implicou redução da preocupação com a compreensão do papel das universidades e instituições de pesquisa nos sistemas nacionais de inovação. No caso brasileiro, em particular, é amplamente disseminada a avaliação de que os avanços no âmbito científico não têm se traduzido em performance semelhante no campo tecnológico (Pacheco; Cruz, 2005: 9; Silva; Melo, 2001: 32; Livro Azul, 2010: 35).

O objetivo deste artigo é contribuir para o debate sobre as relações entre universidades e empresas no Brasil fazendo uso dos resultados de um survey que interrogou 324 firmas que interagiram com instituições acadêmicas. A base de dados é composta majoritariamente por empresas industriais ( $75 \%$ da 
amostra), mas cobre também firmas dedicadas a tecnologias de informação e comunicação, engenharia e $\mathrm{P} \& \mathrm{D}$, outros serviços e mesmo agropecuária e silvicultura. A estratégia básica de investigação envolve a segmentação da indústria de transformação nas quatro categorias de intensidade tecnológica em que a OCDE (Organização para a Cooperação e Desenvolvimento Econômico) divide a atividade industrial e a análise dos resultados obtidos no conjunto das empresas pesquisadas e em cada um desses recortes de intensidade tecnológica. Como o questionário aplicado é consistente com estudos semelhantes realizados fora do Brasil (Cohen et al., 2002), pretende-se que a comparação com a experiência internacional contribua para a análise.

\section{Caracterização da base de dados}

Este artigo é um dos resultados de um extenso esforço de pesquisa sobre a interação universidade-empresa no Brasil e em onze outros países em desenvolvimento, esforço esse que foi inspirado por investigações sobre o mesmo tema realizadas anteriormente nos EUA (Klevorick et al., 1995; Cohen et al., 2002). No caso brasileiro, a pesquisa envolveu, entre outros procedimentos, a tabulação de informações disponíveis no Diretório dos Grupos de Pesquisa do Conselho Nacional de Desenvolvimento Científico e Tecnológico (DGP/ CNPq), um levantamento que interrogou pesquisadores que lideram esses grupos e um survey dirigido às empresas, semelhante ao aplicado nos EUA. Este artigo basicamente reporta os resultados deste último levantamento, doravante designado $B R$ survey, privilegiando um recorte analítico específico: a agregação das respostas segundo uma versão expandida da classificação da OCDE de atividades industriais em categorias de intensidade tecnológica.

O questionário foi enviado a 1.688 empresas $^{3}$ citadas expressamente por pelo menos um grupo de pesquisa registrado no censo de 2006 do DGP/CNPq. A aplicação dos questionários foi feita por meio eletrônico e por telefone entre abril e novembro de 2009. O trabalho exigiu boa dose de persistência das nove equipes em que a pesquisa de campo foi dividida com base em critérios de proximidade geográfica. Após a verificação de consistência das respostas, chegou-se a um número de 324 respostas válidas.

A base de dados é composta majoritariamente por empresas da indústria de transformação (63\% das 324 empresas). As empresas deste ramo de ativi-

3 A rigor, o número de empresas é menor, já que, em alguns casos, unidades diferentes de uma mesma empresa foram alvos da pesquisa. Além disso, algumas das organizações investigadas não são, estritamente falando, empresas. Essas observações são igualmente válidas para o conjunto das empresas que responderam ao questionário. Quatro das empresas entrevistadas o foram em mais de uma unidade local de operação. Essas quatro empresas perfazem um total de 11 respostas. Por outro lado, 11 respondentes não são juridicamente empresas. Este grupo inclui cooperativas, fundações e instituições de direito público. 
dade dividem-se de maneira quase perfeitamente equânime entre as quatro categorias de intensidade tecnológica em que a OCDE segmenta a atividade industrial ${ }^{4}$. A decisão de adotar este critério para agrupar as atividades econômicas procurou conciliar o interesse em repartir a amostra em subconjuntos de empresas mais homogêneos quanto à dinâmica tecnológica e a busca de obter um grau de representatividade superior ao que seria possível caso se optasse por critérios setoriais mais desagregados, como a classificação a dois dígitos da CNAE (Classificação Nacional de Atividades Econômicas).

A composição da amostra de empresas que respondeu o survey impôs, no entanto, a necessidade de avançar além da classificação de categorias de intensidade tecnológica, que tradicionalmente cobre apenas a indústria de transformação. Embora empresas deste ramo predominem de forma clara na base de dados, 121 das respondentes enquadram-se em outros ramos de atividade. No conceito amplo de atividade industrial, incluem-se também firmas que devem ser classificadas nos setores de extração mineral (3\% da amostra) e de serviços de utilidade pública ${ }^{5}$ (9\%). Isto significa que $3 / 4$ das empresas entrevistadas são empresas industriais lato sensu. O levantamento cobriu também empresas da agropecuária (6\%) e de vários setores tipicamente terciários: engenharia e P\&D (7\%), informação e comunicação $(6,5 \%)$ e outros serviços $(6,5 \%)$, categoria que inclui órgãos públicos.

A Tabela 1 apresenta os números absolutos e a frequência relativa de cada um dos agrupamentos setoriais em que a amostra de empresas entrevistadas será dividida ao longo deste artigo. Cabe registrar que a agregação das atividades não manufatureiras obedeceu aos mesmos objetivos do uso das categorias de intensidade tecnológica como critério de segmentação na indústria de transformação, isto é, simultaneamente obter um grau razoável de homogeneidade interna e alcançar, em cada agrupamento, um número de empresas suficiente para que eventuais idiossincrasias das respostas de uma ou outra empresa se diluam.

4 Os estudos da OCDE classificam os setores da indústria de transformação em quatro categorias de acordo com a intensidade em P\&D: baixa tecnologia, média-baixa tecnologia, média-alta tecnologia e alta tecnologia. A classificação parte de dados desagregados no nível de dois dígitos da ISIC (International Standard Industrial Classification), exceto nos casos das indústrias farmacêutica, de material ferroviário e de construção naval, que, embora especificadas num nível mais detalhado de desagregação, são especificamente classificadas de acordo com sua intensidade tecnológica (OECD, 2009).

5 Para os fins deste estudo, os serviços de telecomunicações não foram incluídos na categoria de serviços de utilidade pública. Considerando características de sua dinâmica tecnológica, especialmente a convergência em curso entre muitas das principais tecnologias empregadas nesses setores, esses serviços foram agrupados com outras atividades ligadas às tecnologias de informação. 
TABELA 1. DISTRIBUIÇÃO DAS EMPRESAS POR AGRUPAMENTOS SETORIAIS E DE INTENSIDADE TECNOLÓGICA, BRASIL (2009)

\begin{tabular}{l|cc}
\hline \multicolumn{1}{c|}{ Categorias } & $\mathrm{N}$ & Part. \% \\
\hline Agropecuária e Silvicultura & 18 & $5,6 \%$ \\
Indústrias Extrativas & 11 & $3,4 \%$ \\
Indústrias de Baixa Tecnologia & 50 & $15,4 \%$ \\
Indústrias de Média-Baixa Tecnologia & 51 & $15,7 \%$ \\
Indústrias de Média-Alta Tecnologia & 54 & $16,7 \%$ \\
Indústrias de Alta Tecnologia & 48 & $14,8 \%$ \\
Serviços de Utilidade Pública & 28 & $8,6 \%$ \\
Outros Serviços & 21 & $6,5 \%$ \\
Informação e Comunicação & 21 & $6,5 \%$ \\
Engenharia e P\&D & 22 & $6,8 \%$ \\
\hline Total & 324 & $100,0 \%$ \\
\hline
\end{tabular}

FONTE: Elaboração própria com base em dados do BR Survey, 2009.

As empresas cobertas pela pesquisa distribuem-se de forma bastante equilibrada entre as classes de tamanho: $34 \%$ delas são grandes empresas (500 ou mais empregados), 31\% de médio porte (entre 100 e 499 empregados) e $35 \%$ de pequeno porte (menos de 100 empregados) ${ }^{6}$. No tocante ao controle do capital, 70\% das respondentes declararam ser empresas privadas de capital nacional, $12 \%$ privadas de capital estrangeiro e $6 \%$ empresas públicas, enquanto as empresas restantes (12\%) se identificaram como empresas com controle

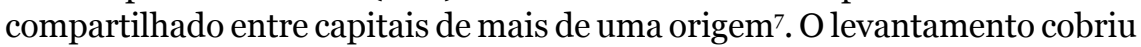
empresas localizadas em quase todas as unidades da federação, excetuandose somente Tocantins e Acre. De toda maneira, a distribuição geográfica das empresas reproduz, em boa medida, a concentração da atividade econômica no País: $48 \%$ delas estão situadas na Região Sudeste, 33\% no Sul, 9\% no Nordeste, $6 \%$ no Norte e $5 \%$ no Centro-Oeste.

A grande maioria das empresas interrogadas declara realizar atividades de pesquisa e desenvolvimento (P\&D). $77 \%$ delas fazem-no de forma contínua, enquanto $14 \%$ de forma apenas ocasional. 30 empresas ( $9 \%$ da amostra) não responderam esta questão, mas mesmo neste subconjunto há empresas que aparentemente executam atividades dessa natureza. Com efeito, apenas 12 empresas (4\%) apontaram gastos nulos e nenhum funcionário alocado ao P\&D. Portanto, embora exista significativa disparidade quanto ao grau de estruturação da atividade ${ }^{8}$, a base de dados se refere a um conjunto de empresas que de forma amplamente majoritária indica a realização de P\&D. Do mesmo modo, a base é composta quase exclusivamente por empresas inovadoras, ao menos no sentido amplo do termo proposto pelo Manual de

6 Das 114 empresas de pequeno porte, 47 são microempresas (14\% da amostra).

7 Das 38 empresas cuja origem do capital é compartilhada, 17 contam com capital estrangeiro ( $5 \%$ da amostra) e as outras 21 (7\%) com capital público e privado, mas sempre nacional.

8 Das 324 empresas, 217 (67\%) disseram possuir um departamento dedicado especificamente à atividade de P\&D. 
Oslo. Apenas dez empresas (3\% da amostra) não introduziram algum produto ou processo que fossem novos ao menos para elas mesmas durante os três anos que antecederam a pesquisa.

\section{Apresentação e análise dos resultados}

Das várias questões que podem ser abordadas a partir da base de dados, convém começar com a avaliação das empresas quanto às fontes de informação para suas atividades inovativas. Com efeito, existem diferenças significativas entre as fontes de informação consideradas mais importantes para sugerir novos projetos de inovação e aquelas privilegiadas na conclusão de projetos, segundo expresso na Figura 1. Os clientes (35\% das empresas) são a fonte mais citada como primordial para a geração de novos projetos, ao passo que a própria linha de produção (25\%) predomina entre as fontes que importam para concluir os projetos. Cada uma dessas fontes assume a segunda posição em importância relativa no âmbito em que a outra é privilegiada. Em terceiro lugar, porém, situam-se as universidades, com parcelas bem parecidas - 13\% e $14 \%$, respectivamente - para ambos os fins. Outras fontes são indicadas bem menos frequentemente como as mais importantes. No caso da conclusão de projetos há, todavia, maior desconcentração das fontes e institutos de pesquisa (9\%), empresas de consultoria e P\&D externo (8\%) e fornecedores (6\%) assumem papéis bastante relevantes.

Desagregando-se a análise, percebe-se que os clientes são a fonte de informação mais importante para sugerir novos projetos em nada menos do que sete dos dez agrupamentos setoriais, incluindo todas as divisões da indústria de transformação independentemente da intensidade tecnológica, a extração mineral, os serviços de informação e comunicação e as atividades de engenharia e P\&D, de acordo com a Tabela A.1 do Apêndice. Em outros serviços, as linhas de produção da própria empresa predominam, mas na agropecuária e nos serviços de utilidade pública a primazia cabe às universidades, que foram indicadas como fonte mais importante por pelo menos $10 \%$ das empresas em cinco outros agrupamentos de atividades. É de se notar também a relevância dos institutos de pesquisa nas mesmas categorias em que as universidades predominam. Em outra direção, destaca-se o fato de tanto universidades quanto institutos de pesquisa serem muito pouco citados nas indústrias de alta tecnologia e nos serviços de informação e comunicação. 


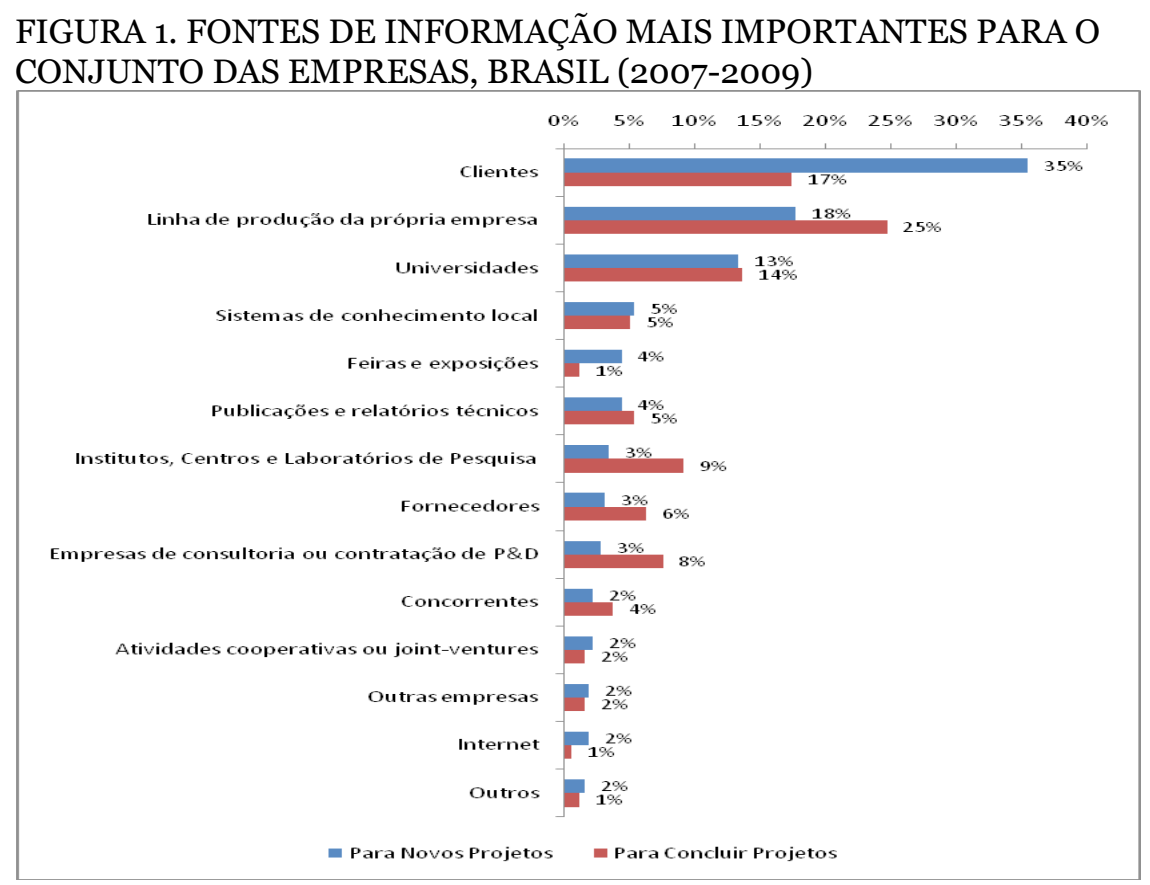

FONTE: Elaboração própria com base em dados do BR Survey, 2009.

O panorama é setorialmente mais diversificado no tocante às fontes de informação para concluir projetos, segundo a Tabela A.2 do Apêndice. Muito importantes em quase todas as categorias, as linhas de produção próprias predominam na indústria de transformação - exceto nas indústrias de alta tecnologia -, em serviços de informação e comunicação e em outros serviços. Os clientes são a fonte mais importante em serviços de engenharia e P\&D e nas indústrias de alta tecnologia e extrativa. Em serviços de utilidade pública, as universidades também neste âmbito predominam, mas na agropecuária são superadas pelas empresas de consultoria e P\&D externo, que têm grande importância também para a extração mineral. Por sua vez, os institutos de pesquisa são referidos como a fonte mais importante por uma parcela relevante das empresas em todos os agrupamentos de atividades, alcançando 10\% ou mais das empresas em cinco deles.

A base de dados permite encarar a questão das fontes de informação para as atividades inovativas sob um prisma um tanto diferente, qual seja o de todas as fontes em que essas atividades se basearam, independentemente da hierarquia de importância entre elas. Essa perspectiva é conveniente principalmente porque corresponde à que foi adotada no estudo de Cohen et al (2002) com 1.287 empresas industriais dos EUA. Os resultados obtidos nos 
PINHO, M. A visão das empresas sobre as relações entre universidade...

dois surveys podem ser comparados por meio da Figura 2. Segundo este novo critério, a primazia dos clientes e das linhas de produção da própria empresa não só se repete nos dados brasileiros, mas também se manifesta nos dados norte-americanos ${ }^{9}$. É igualmente reiterada a preponderância dos clientes na sugestão de novos projetos e das linhas de produção em sua conclusão, tanto aqui quanto nos EUA.

\section{FIGURA 2 . FONTES DE INFORMAÇÃO PARA PROJETOS DE INOVAÇÃO NO BRASIL (2007-2009) E NOS EUA (1992-1994)}

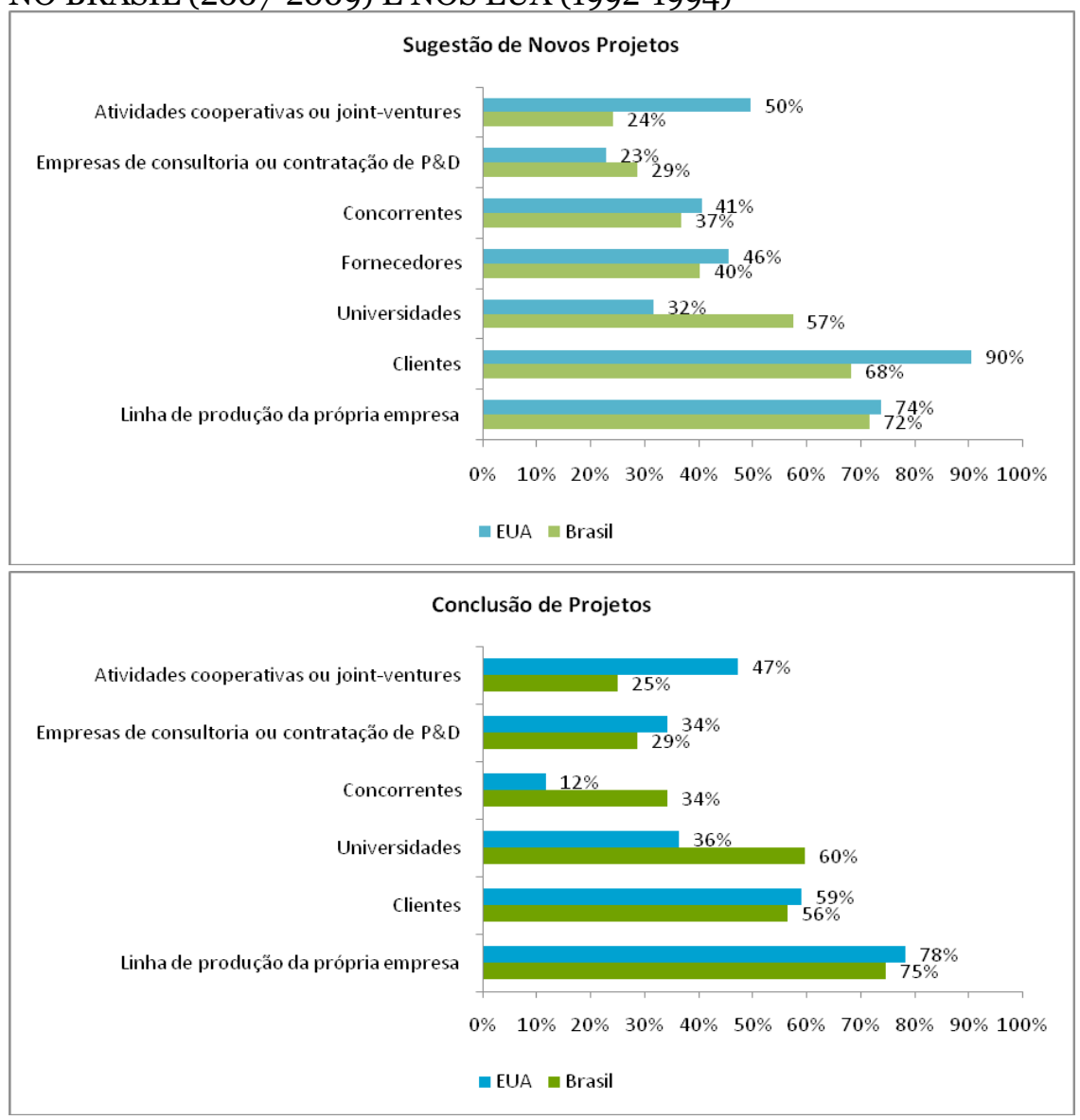

FONTE: Elaboração própria com base em dados do BR Survey e de Cohen et al (2002).

9 A rigor, o estudo de Cohen et al. (2002) posiciona os clientes como terceira fonte de maior importância para concluir projetos, ligeiramente atrás dos fornecedores. 
Há, no entanto, grande diferença na frequência com que são citadas as universidades, muito maior no caso brasileiro. Isso vale tanto para a sugestão de novos projetos ( $57 \%$ dos respondentes no Brasil e $32 \%$ nos EUA) quanto para a conclusão de projetos (60\% x 36\%), com o agravante de que no estudo de Cohen et al. (2002) a categoria pesquisada era mais abrangente, incluindo num único item universidades e institutos públicos de pesquisa. Considerando-se em nossa base de dados as empresas que mencionaram pelo menos uma das duas opções - universidades ou institutos de pesquisa - como fontes para as atividades inovativas, as proporções no Brasil sobem respectivamente para $65 \%$ e $71 \%$, o dobro dos valores encontrados no estudo norte-americano. Em contrapartida, as referências a joint-ventures, em ambas as etapas das atividades inovativas, e aos fornecedores, sobretudo no caso da conclusão de projetos, são muito mais numerosas nos EUA, conforme expresso na Figura 2.

É possível que a maior frequência das citações às Universidades tenha alguma relação com diferenças entre o conjunto de empresas entrevistadas nos dois países. Em todo caso, pode ser descartada a hipótese de um viés decorrente das distintas composições setoriais dos dois conjuntos de empresas. Cohen et al. (2002) investigaram apenas firmas que fazem P\&D e atuam na indústria de transformação. Tomando-se apenas as empresas com esta mesma inserção setorial em nossa pesquisa, cai um pouco a menção às universidades como fonte de informação para atividades inovativas, mas as frequências - 51\% para sugerir novos projetos e $57 \%$ para concluir projetos - continuam a ser muito superiores às encontradas no estudo realizado nos EUA. Viés mais ponderável deve advir da origem da lista de firmas visadas pela pesquisa de campo realizada no Brasil. O alvo desta pesquisa foram, como já foi dito, as empresas mencionadas pelos pesquisadores no Diretório de Grupos de Pesquisa do CNPq. O fato de que essas empresas tiveram relação com grupos de pesquisa sugere que elas tendam a valorizar as universidades como fonte de informação, provavelmente mais do que a média das empresas. Contudo, deve-se recordar que, mesmo com esse viés de origem, 19\% das empresas entrevistadas não apontaram nem universidades nem institutos de pesquisa como fonte de informação para atividades inovativas.

Para se avaliar em termos comparativos a frequência com que as universidades são citadas como fonte de informação para as atividades inovativas das empresas pode-se recorrer a outras fontes de dados, como os fornecidos pela brasileira Pesquisa de Inovação Tecnológica (PINTEC) e pela europeia Community Innovation Survey (CIS). A comparabilidade entre os resultados obtidos, ainda que não seja plena, é favorecida pela inspiração de ambas as pesquisas nas recomendações das revisões mais recentes do Manual de Oslo e pelo uso neste artigo de informações referentes a um mesmo período de tempo, o triênio 2006-2008. 
As duas pesquisas cobrem um universo de empresas mais abrangente do que os levantamentos anteriormente resenhados. Não surpreendentemente, desenham um quadro em que o papel da universidade como fonte de informação para a inovação é bem menos significativo, não figurando entre as mais frequentemente mencionadas pelas empresas interrogadas. De todo modo, como se pode conferir na Figura 3, a proporção de empresas inovadoras que consideraram as universidades fonte de informação de alta importância é maior no Brasil (6,8\%) do que na média dos países da União Europeia (4,3\%) em que o mesmo dado está disponível ${ }^{10}$. Mais do que isso, a proporção registrada no Brasil é maior do que em todos os países integrantes da União Europeia, com a única exceção da Hungria.

FIGURA 3. PROPORÇÃO DAS EMPRESAS INOVADORAS QUE ATRIBUEM ALTA IMPORTÂNCIA ÀS UNIVERSIDADES COMO FONTE DE INFORMAÇÃO PARA ATIVIDADES INOVATIVAS, BRASIL E UNIÃO EUROPEIA (2006-2008)

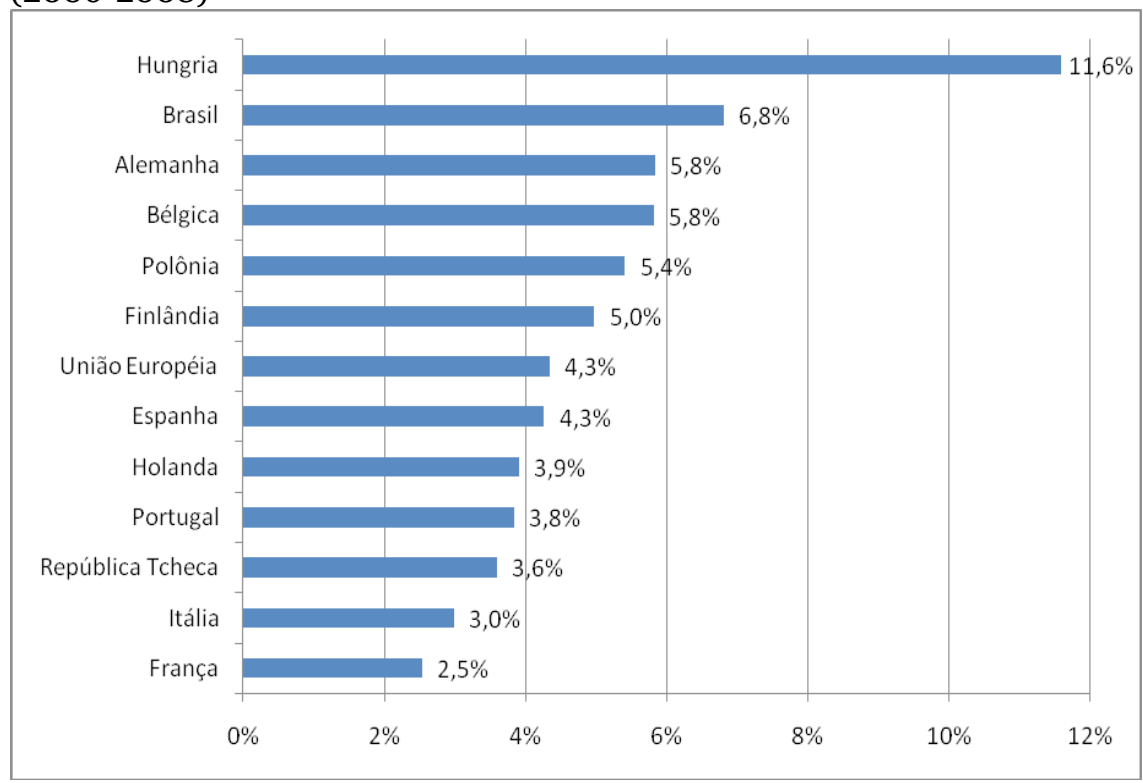

FONTE: Elaboração própria com base em dados da Pintec (IBGE, 2010) e da CIS (European Commission, 2011).

10 Comparando os resultados de surveys de inovação realizados em meados da década passada na África do Sul e na União Europeia, Petersen e Rumbelow (2008: 10) identificaram um quadro semelhante, isto é, as empresas sul-africanas atribuíram maior importância às universidades e institutos públicos de pesquisa como fontes de informação para a inovação do que as europeias. 
FIGURA 4. IMPORTÂNCIA DAS FORMAS DE INTERAÇÃO COM UNIVERSIDADES E INSTITUTOS DE PESQUISA PARA O CONJUNTO DAS EMPRESAS ENTREVISTADAS, BRASIL (2009)

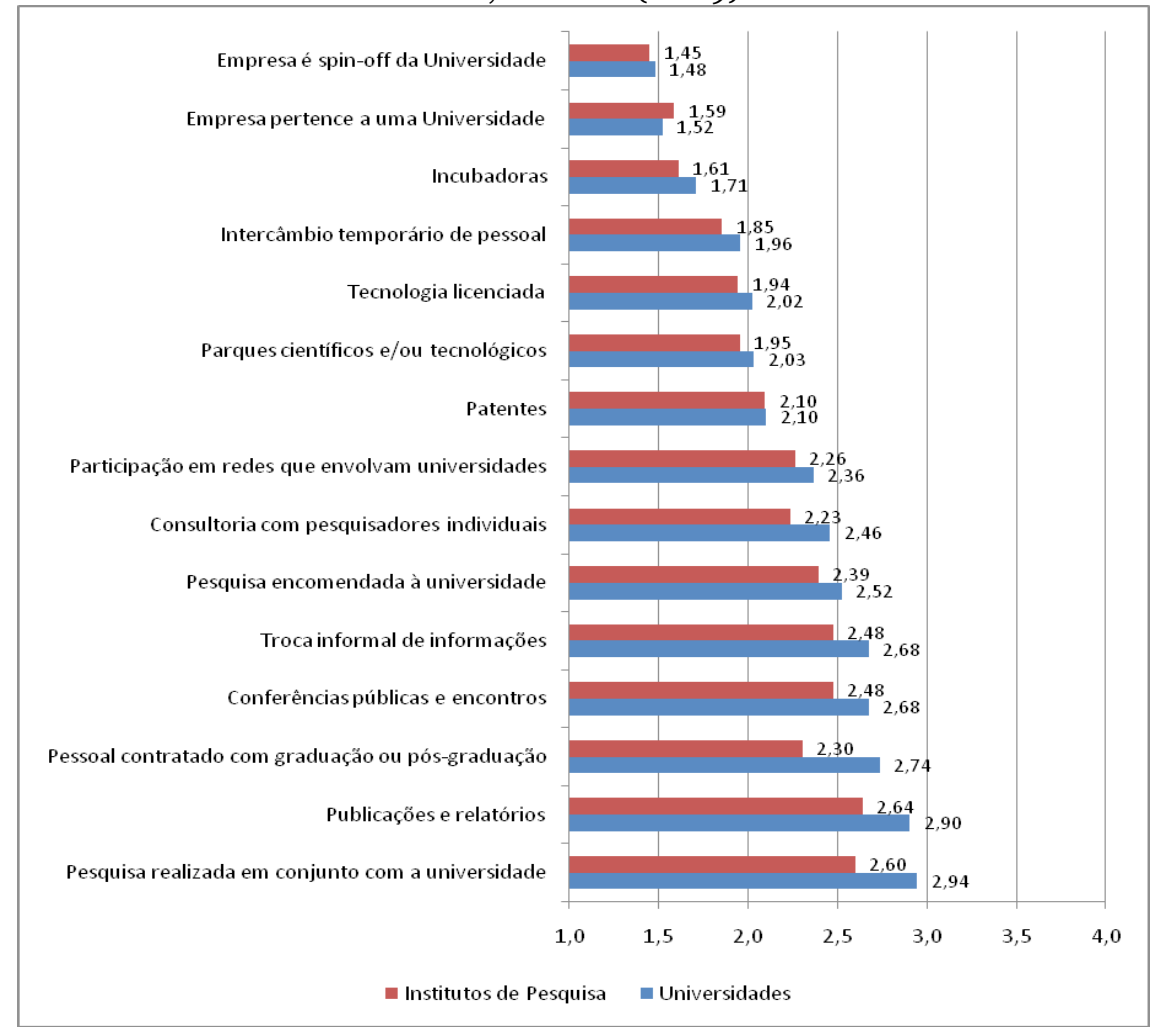

NOTA: 1) Sem importância; 2) Pouco Importante; 3) Moderadamente importante; 4) Muito importante.

FONTE: Elaboração própria com base em dados do BR Survey, 2009.

Retornando aos dados do BR survey e enfocando agora as formas de interação (ou modos de relacionamento) com o conhecimento das universidades e institutos de pesquisa, sobressai imediatamente o fato de as empresas, em todos os agrupamentos de atividade, tenderem a atribuir menor importância à maioria dos mecanismos costumeiramente enfatizados pelos cânones da gestão da tecnologia: licenciamento de tecnologia, incubadoras, parques tecnológicos e spin-offs ${ }^{11}$ (Figura 4). Pesquisa conjunta, publicações, contratação de pessoal, conferências, troca informal de informações e pesquisa encomendada são, todos, meios de interação que, na média das empresas entrevistadas, atingem o grau de moderadamente importantes e superam por boa margem aqueles instrumentos usuais de transferência de tecnologia. Os 11 Uma hipótese, benevelonte, que pode ser aventada para explicar esse resultado é que os efeitos dos mecanismos tradicionais de transferência de tecnologia podem até ser poderosos, mas são concentrados num número pequeno de empresas intensamente favorecidas por eles. 
resultados aqui obtidos são consistentes com os encontrados por Cohen $e t$ al. (2002: 15), que identificou o licenciamento de tecnologia como o segundo menos importante numa lista de dez canais de conexão entre universidades e empresas. Avaliando os resultados para o conjunto das empresas, encontra-se também mais convergência do que divergência entre os dois surveys, mas a hierarquia de formas de interação está longe de ser exatamente a mesma ${ }^{12}$.

Os mecanismos acima identificados como mais importantes no conjunto da amostra têm também sua importância reconhecida como pelo menos moderada pela média das opiniões em quase todos os agrupamentos setoriais ${ }^{13}$, conforme a Tabela A.3 do Apêndice. É mais localizado o reconhecimento da relevância da consultoria de pesquisadores individuais - cuja média setorial só alcança o patamar moderadamente importante em agropecuária, indústrias de baixa tecnologia e serviços de informação e comunicação - e da participação em redes que envolvem universidades (agropecuária, extração mineral e serviços de utilidade pública).

Outra análise que pode ser feita das respostas sobre as formas de interação se concentra nos meios tidos como mais importantes em cada agrupamento de setores. Destacam-se, uma vez mais, a pesquisa conjunta - destaque na agropecuária, em indústrias de média-baixa tecnologia, na extração mineral e em serviços de utilidade pública - e as publicações - engenharia e P\&D, serviços de utilidade pública e indústrias de baixa tecnologia e de média-alta tecnologia. Fogem claramente desse padrão somente os serviços de informação e comunicação, que privilegiam a contratação de pessoal e a troca informal de informações.

Esses resultados são corroborados por outra questão, que interrogou as empresas sobre a importância de resultados e recursos da Universidade para suas atividades inovativas, segundo a Tabela 2. Das quatro alternativas - resultados de pesquisas, novas técnicas e instrumentos, laboratórios e metrologia e protótipos -, apenas esta última apresenta uma posição claramente inferior. Os resultados de pesquisa atingem a maior pontuação não apenas no conjunto das empresas entrevistadas, mas em nove dos dez agrupamentos setoriais. A única exceção volta a ser dos serviços de informação e comunicação, em que se atribui maior peso às novas técnicas e instrumentos ${ }^{14}$. Cabe acrescentar que essa preponderância dos resultados de pesquisa também foi encontrada

\footnotetext{
12 A comparação com os resultados apresentados por Cohen et al. (2002) neste tema exigiu a tabulação dos dados num formato um tanto diferente do apresentado no Gráfico 4 e na Tabela A.3. Considerando-se a proporção de respondentes que indicou cada fonte como moderadamente ou muito importante, as publicações são o canal mais proeminente tanto nos EUA quanto no Brasil. Por aqui, no entanto, as empresas atribuem importância muito maior tanto à pesquisa realizada em conjunto com a universidade quanto à contratação de pessoal. Troca informal de informações e conferências são muito relevantes em ambos os casos, mas assumem uma posição relativa mais elevada nos EUA. Por fim, registre-se a inversão de hierarquia entre consultoria individual e pesquisa encomendada: esta é, em termos relativos, mais importante aqui do que lá e vice-versa. 13 Esses resultados são válidos quando as empresas avaliam a interação tanto com as universidades quanto com os institutos de pesquisa, mas deve-se notar que neste caso atribui-se menor importância a relacionamentos mais formais, como a pesquisa conjunta e, sobretudo, a encomendada. Algo semelhante ocorre, ainda que por razões diferentes, em relação à contratação de pessoal com graduação ou pós-graduação.

14 As peculiaridades encontradas nesse agrupamento permitem levantar a hipótese de que haja nos serviços de informação e comunicação um padrão específico de interação universidade-empresa.
} 
por Cohen et al. (2002: 9) para o conjunto da indústria de transformação nos EUA. A propósito, a agregação dos resultados setoriais apresentados por esses autores mostra que também lá esse resultado permanece válido em cada uma das categorias de intensidade tecnológica.

A análise das respostas sobre a relevância das áreas de conhecimento científico para as atividades de pesquisa da empresa apontou, uma vez mais, mais convergência do que divergência em relação aos achados de Cohen et al. (2002). Ainda que esses autores tenham adotado um critério um pouco diferente para a análise dos dados - a porcentagem de respondentes que indicou cada área como moderadamente importante ou importante -, a hierarquia das áreas não é muito diferente. Nos EUA, destacaram-se, pela ordem, ciência dos materiais, computação, química e engenharias mecânica, elétrica e química. Em nossa amostra, a ordenação dos resultados obtidos a partir da escala likert começa com engenharia de materiais e computação e prossegue com engenharia química, química, engenharia mecânica, agronomia e engenharia elétrica, conforme a Tabela A.4 do Apêndice. Portanto, a diferença mais importante é a presença no Brasil da agronomia no rol das áreas de conhecimento de maior importância.

TABELA 2. IMPORTÂNCIA DE RESULTADOS E RECURSOS DA UNIVERSIDADE PARA AS ATIVIDADES INOVATIVAS DA EMPRESA, BRASIL (2007-2009)

\begin{tabular}{|c|c|c|c|c|}
\hline Categorias & $\begin{array}{c}\text { Resultados } \\
\text { de Pesqui- } \\
\text { sas }\end{array}$ & Protótipos & $\begin{array}{l}\text { Novas Téc- } \\
\text { nicas e Ins- } \\
\text { trumentos }\end{array}$ & $\begin{array}{c}\text { Laborató- } \\
\text { rios e Me- } \\
\text { trologia }\end{array}$ \\
\hline $\begin{array}{l}\text { Agropecuária } \\
\text { e Silvicultura }\end{array}$ & $\mathbf{3 , 3 9}$ & 1,89 & 3,17 & 2,83 \\
\hline Engenharia e P\&D & 3,23 & 1,82 & 3,09 & 2,36 \\
\hline $\begin{array}{l}\text { Indústrias de Alta } \\
\text { Tecnologia }\end{array}$ & 3,02 & 2,23 & 2,73 & 2,90 \\
\hline $\begin{array}{l}\text { Indústrias de Baixa } \\
\text { Tecnologia }\end{array}$ & 3,14 & 2,34 & 2,74 & 2,78 \\
\hline $\begin{array}{l}\text { Indústrias de Média- } \\
\text { Alta Tecnologia }\end{array}$ & $\mathbf{2 , 8 3}$ & 2,37 & 2,48 & 2,72 \\
\hline $\begin{array}{l}\text { Indústrias de Média- } \\
\text { Baixa Tecnologia }\end{array}$ & 2,96 & 2,57 & 2,86 & 2,94 \\
\hline Indústrias Extrativas & 3,64 & 3,00 & 3,55 & 3,45 \\
\hline $\begin{array}{l}\text { Informação } \\
\text { e Comunicação }\end{array}$ & 2,90 & 2,62 & 3,29 & 2,14 \\
\hline Outros Serviços & 2,90 & 2,10 & 2,86 & 2,33 \\
\hline $\begin{array}{l}\text { Serviços de Utilidade } \\
\text { Pública }\end{array}$ & 3,25 & 2,82 & 3,18 & 2,93 \\
\hline $\begin{array}{c}\text { Total } \\
\end{array}$ & 3,06 & $\mathbf{2 , 3 7}$ & $\mathbf{2 , 8 7}$ & 2,75 \\
\hline
\end{tabular}

NOTA: 1) Sem importância; 2) Pouco Importante; 3) Moderadamente importante; 4) Muito importante. FONTE: Elaboração própria com base em dados do BR Survey, 2009. 
De todo modo, duas áreas de conhecimento parecem sobressair um pouco mais como focos de interesse para as atividades de pesquisa das empresas: ciência da computação, apontada como mais importante nos serviços de informação e comunicação, indústrias de alta tecnologia e serviços de engenharia e $\mathrm{P} \& \mathrm{D}$, e engenharia de materiais e metalúrgica, prevalecente em indústrias extrativas, de média-baixa tecnologia e média-alta tecnologia. Resultados esperados são encontrados, como o privilégio à agronomia na agropecuária, à tecnologia de alimentos nas indústrias de baixa tecnologia e à engenharia elétrica em serviços de utilidade pública. Não há, porém, explicação trivial para o destaque das ciências biológicas em outros serviços.

TABELA 3. FINANCIAMENTO USUAL DA COLABORAÇÃO DA EMPRESA COM A UNIVERSIDADE, BRASIL (2009)

\begin{tabular}{|c|c|c|c|}
\hline Categorias & Próprios (\%) & Públicos (\%) & Terceiros (\%) \\
\hline $\begin{array}{l}\text { Agropecuária } \\
\text { e Silvicultura }\end{array}$ & 63,6 & 34,6 & 1,8 \\
\hline Engenharia e P\&D & 66,6 & 25,7 & 7,7 \\
\hline $\begin{array}{l}\text { Indústrias de Alta } \\
\text { Tecnologia }\end{array}$ & 78,1 & 21,1 & 0,8 \\
\hline $\begin{array}{l}\text { Indústrias de Baixa } \\
\text { Tecnologia }\end{array}$ & 81,1 & 16,9 & 2,1 \\
\hline $\begin{array}{l}\text { Indústrias de Média-Alta } \\
\text { Tecnologia }\end{array}$ & 78,1 & 21,0 & 0,9 \\
\hline $\begin{array}{l}\text { Indústrias de Média- } \\
\text { Baixa Tecnologia }\end{array}$ & 81,7 & 16,3 & 2,0 \\
\hline Indústrias Extrativas & 74,5 & 25,5 & 0,0 \\
\hline $\begin{array}{l}\text { Informação } \\
\text { e Comunicação }\end{array}$ & 68,9 & 30,4 & 0,7 \\
\hline Outros Serviços & 75,9 & 24,1 & 0,0 \\
\hline $\begin{array}{l}\text { Serviços de Utilidade } \\
\text { Pública }\end{array}$ & 82,2 & 17,8 & 0,0 \\
\hline Total & 77,3 & $\mathbf{2 1 , 2}$ & $\mathbf{1}, 5$ \\
\hline
\end{tabular}

FONTE: Elaboração própria com base em dados do BR Survey, 2009.

As empresas foram interrogadas também sobre como avaliavam os resultados da colaboração com a Universidade. Neste tema, os resultados são francamente auspiciosos. Considerando-se tanto projetos já concluídos quanto iniciativas ainda em andamento, oito em cada nove empresas julgam a colaboração bem-sucedida, segundo a Tabela A.5 do Apêndice. Não obstante os números sejam positivos em todos os agrupamentos setoriais, percebem-se taxas de sucesso menores justamente em atividades de alta intensidade tecnológica, como indústrias de alta tecnologia, engenharia e P\&D e serviços de informação e comunicação. 
A colaboração com as universidades seria financiada, segundo as empresas, majoritariamente pelos seus próprios recursos (77\% na média das entrevistadas). Ainda assim, os recursos públicos têm um papel que é relevante na média (21\% dos recursos) e, sobretudo, em atividades como a agropecuária (35\%), serviços de informação e comunicação (30\%) e engenharia e P\&D (26\%), de acordo com a Tabela 3. Numa atividade vinculada ao investimento em inovação, não é surpreendente que a participação de recursos de terceiros, excetuando-se os públicos, seja quase sempre inexpressiva e, na grande maioria dos casos, nula.

\section{Considerações Finais}

A análise da base de dados apresentada na seção anterior permitiu chegar a um bom número de conclusões, as quais cabe aqui ratificar e sintetizar:

(1) Embora os clientes sejam a fonte primordial para a geração de novos projetos inovativos e a linha de produção predomine na conclusão dos projetos, as universidades são bastante importantes para ambos os fins, ainda que menos destacadas nas indústrias de alta tecnologia e nos serviços de informação e comunicação.

(2) Pesquisa conjunta, publicações, contratação de pessoal, conferências, troca informal de informações e pesquisa encomendada são meios de interação que superam por boa margem a relevância de instrumentos usuais de transferência de tecnologia, como licenciamento de tecnologia, incubadoras, parques tecnológicos e spin-offs. Embora haja diferenças em relação a alguns itens, a preponderância de meios vinculados à divulgação pública do conhecimento científico é consistente com os resultados encontrados nos EUA por Cohen et al. (2002).

(3) De quatro alternativas de resultados e recursos da Universidade importantes para a inovação nas empresas - resultados de pesquisas, novas técnicas e instrumentos, laboratórios e metrologia e protótipos -, apenas a última tem relevância claramente inferior. Contudo, em nove dos dez agrupamentos setoriais os resultados de pesquisa são julgados os mais importantes.

(4) Os dois principais focos de interesse para as pesquisas das empresas em termos de áreas de conhecimento são ciência da computação, a mais importante em atividades de alta intensidade tecnológica, e engenharia de materiais e metalúrgica, prevalecente em indústrias extrativas, de médiabaixa tecnologia e média-alta tecnologia. Essas duas áreas também foram identificadas em Cohen et al. (2002: 10) como aquelas cujos impactos são 
PINHO, M. A visão das empresas sobre as relações entre universidade...

(i) mais importantes no conjunto da indústria de transformação e (ii) importantes para um maior número de setores. A principal diferença entre os dois surveys neste tema é a posição bastante relevante que assume em nosso levantamento a agronomia.

(5) É auspiciosa a avaliação das empresas dos resultados da colaboração com a Universidade - oito em cada nove julgam-na bem-sucedida -, mas taxas de sucesso menores ocorrem justamente em atividades mais intensivas em tecnologia.

(6) Os dados confirmam a existência de uma relação das empresas com as universidades e institutos de pesquisa particularmente intensa e proveitosa na agropecuária (Rapini et al., 2006). Neste ramo, as universidades são a segunda fonte de informação mais importante para concluir projetos e a primeira para sugerir novos projetos, âmbito em que os institutos de pesquisa dividem a terceira posição. A relevância da agronomia é, como já se salientou, a principal particularidade da relação de áreas de conhecimento mais importantes no Brasil na comparação com os EUA. As relações das universidades com empresas deste setor, além de se destacarem pela importância, diferenciam-se também pela maior relevância do financiamento público e por uma posição de vulto da pesquisa conjunta com a universidade entre as modalidades de interação.

A maior contribuição deste artigo, no entanto, é lançar dúvidas sobre o senso comum em relação à intensidade das relações entre universidades e empresas no Brasil. As evidências obtidas pela comparação não só entre os resultados aqui reportados e os apresentados por Cohen et al. (2002) como também entre os dados da PINTEC e da CIS indicam que, no mínimo, não há sustentação para a noção de que as empresas brasileiras valorizam menos a contribuição das universidades para seu esforço inovativo do que suas congêneres dos EUA e da União Européia ${ }^{15}$. Embora destoe da visão convencional sobre o assunto, essa conclusão é consistente com estudos recentes sobre o histórico dessa relação (Suzigan \& Albuquerque, 2010) e a produção de pesquisadores em áreas acadêmicas associadas à avicultura, como a veterinária, a zootecnia e a biotecnologia (Murakami, 2011). O primeiro desses estudos mostra que as universidades e instituições de pesquisa cumpriram um papel fundamental para o desenvolvimento de alguns dos setores de atividade que mais se destacam em desempenho exportador na economia brasileira. O segundo demonstra a expressiva participação de autores vinculados a empresas nas redes de colaboração dos mais produtivos pesquisadores brasileiros naquele campo e, em particular, a onipresença de temas diretamente aplicados aos interesses tecnológicos do setor produtivo na relação de teses e dissertações

\footnotetext{
15 Uma das bases dessa percepção bastante difundida é o reconhecimento de que o ambiente institucional, no sentido amplo, teria sido até muito recentemente hostil ao relacionamento entre universidades e empresas. Os dados sugerem que as restrições talvez tenham sido menos efetivas para obstruir essas relações do que para turvar sua visibilidade.
} 
orientadas por esses pesquisadores.

À luz das evidências anteriores, é mais razoável admitir que as relações entre universidades e empresas no Brasil não apenas existem, mas são relativamente intensas. Coerentemente, porém, com o perfil das demandas tecnológicas colocadas pelas empresas, o relacionamento não costuma estar voltado a inovações de maior alcance, calcadas na vanguarda do conhecimento científico. O escopo dessas relações seria, mais do que condicionado, definido e restringido por características estruturais da dinâmica tecnológica periférica. No caso específico do Brasil, essa dinâmica se caracteriza, de um lado, pelo peso menor que têm na estrutura econômica aqueles setores que ditam o ritmo da mudança tecnológica e, de outro, pela adoção pelas empresas de estratégias competitivas em que as funções ligadas à inovação são hierarquicamente menos importantes (Zucoloto; Toneto Jr., 2005; Furtado; Carvalho, 2005).

Em países que passam por processos de desenvolvimento retardatários - mesmo naqueles que avançam substancialmente - as demandas tecnológicas postas pelas empresas à Universidade têm uma natureza diferente das que tipicamente ocorrem nos países desenvolvidos. Ao menos enquanto as empresas daqueles países não se colocam em condições de concorrer de frente com as líderes mundiais, a inovação exerce um papel menos crítico na conduta das empresas e as estratégias tecnológicas, menos ambiciosas, estão voltadas mais propriamente a processos de difusão e absorção. Como a chamada literatura incrementalista enfatizou, não se deve imaginar que esses processos sejam fáceis nem automáticos, já que a adoção de novas tecnologias é apenas o primeiro movimento de uma trajetória em que o esforço de construção de competências de produção e de investimento é um requisito para a absorção efetiva da tecnologia, incluindo as capacidades de operá-la, melhorá-la e adaptá-la às circunstâncias locais (Dahlman et al., 1987; Canuto, 1993). Contudo, o fato de essas trajetórias de absorção de tecnologia serem duras e seletivas não implica que, mesmo nas empresas bem-sucedidas, venham a culminar na constituição de capacidades de inovação, resultado que é muito mais exceção do que regra. Considerando a mobilidade da fronteira tecnológica e a dependência das dinâmicas inovativas de recursos externos às empresas, deve-se presumir que a construção dessas capacidades requer uma muitíssimo exigente evolução conjunta de competências internas das empresas e de outros agentes dos sistemas nacionais de inovação.

No contexto que prevalece em países como o Brasil, as demandas tecnológicas das empresas tendem a ser, cabe insistir, diferentes das que são postas nos países que lideram em escala mundial a dinâmica dos processos de inovação. Até por conta do caráter retardatário de seu desenvolvimento, as empresas dispõem de canais - imperfeitos, é verdade - de acesso a fontes externas de conhecimento: matrizes, fornecedores, concorrentes estrangeiros e empresas de engenharia e consultoria. Neste caso, o problema tecnológico fundamental 
não é o da geração de uma solução nova no sentido estrito do termo. Para quem vem depois, a decisão de criar algo inteiramente novo tem que ser contrastada com a alternativa - muitas vezes vantajosa em custos, riscos, tempo e exigência de capacidades - de fundar suas estratégias tecnológicas na difusão de conhecimento desenvolvido fora da empresa ${ }^{16}$.

De toda maneira, mesmo nessas circunstâncias, existe um espaço importante para a interação com a universidade. Primeiramente, a própria absorção de tecnologias externas pode requerer o auxílio de universidades e institutos de pesquisa, já que a presença de componentes tácitos e, em alguns casos, a complexidade inerente do conhecimento tecnológico impedem que a transferência da tecnologia se concretize sem o uso de recursos e competências que muitas vezes não estão disponíveis dentro das empresas. Além desse preenchimento de lacunas de conhecimento, mesmo quando não se atinge o estágio de competência requerido para inovações de mais largo alcance, haverá um espaço - de extensão variável de acordo com as oportunidades tecnológicas de cada setor, mas muitas vezes rico e importante - para desenvolvimentos tecnológicos com vistas a adaptações, melhorias, desdobramentos e, sobretudo, $o$ atendimento de especificidades locais ${ }^{17}$. Esse espaço é, portanto, diferente daquele em que atuam as universidades de ponta nas dinâmicas inovativas vigentes nos países centrais, mas não é necessariamente menor nem menos importante para as empresas.

Por outro lado, é preciso considerar que as capacidades científicas da Universidade no Brasil provavelmente são insuficientes para lastrear inovações mais radicais, notadamente em setores mais intensivos em P\&D, cuja dinâmica é, de acordo com a tipologia de Pavitt (1984), baseada em ciência. Os problemas que transpareceram na análise dos dados de indústrias de alta tecnologia e serviços vinculados a tecnologias de informação e comunicação talvez possam ser interpretados como resultantes de uma dinâmica tecnológica que coloca requisitos mais exigentes e rigorosos para a base científica. Numa perspectiva mais ampla, ilustram a noção de que processos bem-sucedidos de cathcingup requerem uma coevolução das capacidades tecnológicas das empresas e científicas da Universidade.

\footnotetext{
16 Naturalmente, enquanto prevalecer, esta alternativa estratégica acaba por limitar a construção das capacidades dinâmicas da firma e restringir o alcance de sua posição competitiva.

17 O contexto das necessidades de tecnologias apropriadas a condições específicas do País na agricultura tropical provavelmente ajuda a explicar a relevância já destacada da interação universidade-empresa na agropecuária.
} 


\section{Referências}

CANUTO, O. (1993). “Aprendizado Tecnológico na Industrialização Tardia”. Economia e Sociedade 2: 171-189.

COHEN, W. M. \& NELSON, R. \& WALSH, J. P. (2002). "Links and Impacts: The Influence of Public Research on Industrial R\&D”. Management Science 48 (1): 1-23.

DAHLMAN, C. \& ROSS-LARSON, B. \& WESTPHAL, L. (1987). "Managing Technological Development: Lessons from the Newly Industrialising Countries". World Development 15 (6): 759-775.

EUROPEAN COMMISSION (2011). Science, Technology and Innovation in Europe. Luxembourg: Publications Office of the European Union.

FURTADO, A. T. \& CARVALHO, R. Q. (2005). "Padrões de Intensidade Tecnológica na Indústria Brasileira: Um Estudo Comparativo com os Países Centrais”. São Paulo em Perspectiva 19 (1): 70-84.

INSTITUTO BRASILEIRO DE GEOGRAFIA E ESTATÍSTICA (2010). Pesquisa de Inovação Tecnológica - 2008. Rio de Janeiro: IBGE.

KLEVORICK, A. \& LEVIN, R. \& NELSON, R. \& WINTER, S. (1995). "On the Sources and Significance of Inter- Industry Differences in Technological Opportunities". Research Policy 24(2): 835-851.

LIVRO AZUL da $4^{\text {a }}$ Conferência Nacional de Ciência e Tecnologia e Inovação para o Desenvolvimento Sustentável. (2010). Brasília: MCT/CGEE.

MURAKAMI, T. (2011). As Redes de Valor do Conhecimento como Geradoras e Difusoras do Progresso Técnico para as Atividades Agropecuárias: O Caso da Avicultura Brasileira. Campinas: Dissertação de Mestrado. Universidade Estadual de Campinas, Departamento de Política Científica e Tecnológica.

ORGANISATION FOR ECONOMIC CO-OPERATION AND DEVELOPMENT. (2009). OECD Science, Technology and Industry Scoreboard. OECD Publishing.

PACHECO, C. A. \& CRUZ, C. H. B. (2005). "Instrumentos para o Desenvolvimento: Desafios para C\&T e Inovação em São Paulo”. São Paulo em Perspectiva 19 (1): 3-24.

PAVITT, K. (1984). "Sectoral patterns of technical change toward a taxonomy and a theory." Research Policy 13: 343-373.

PETERSEN, I. H. \& RUMBELOW, J. (2008). "University-Firm Interaction in South Africa: Extent and Intensity". VI Globelics Conference. 
PINHO, M. A visão das empresas sobre as relações entre universidade...

RAPINI, M. \& ALBUQUERQUE, E. M. \& SILVA, L. \& SOUZA, S. \& RIGHI, H. \& CRUZ, W. (2006). "Spots of Interaction: An Investigation of the Relationship Between Firms and Universities in Minas Gerais, Brazil". Texto para Discussão, oㅡ 286, Belo Horizonte: UFMG/Cedeplar.

SILVA, C. G. \& MELLO, L. C. P. (Orgs.). (2001). Ciência, Tecnologia e Inovação: Desafios para a Sociedade Brasileira (Livro Verde). Brasília: $\mathrm{MCT} / \mathrm{ABC}$.

SUZIGAN, W. \& ALBUQUERQUE, E. M. (2011). “The Underestimated Role of Universities for the Brazilian System of Innovation". Revista de Economia Política 31 (1): 3-30.

ZUCOLOTO, G. \& TONETO JR, R. (2005). "Esforço Tecnológico da Indústria de Transformação Brasileira: Uma Comparação com Países Selecionados”. Revista de Economia Contemporânea 9(2): 337-365. 
PINHO, M. A visão das empresas sobre as relações entre universidade...

Apêndice

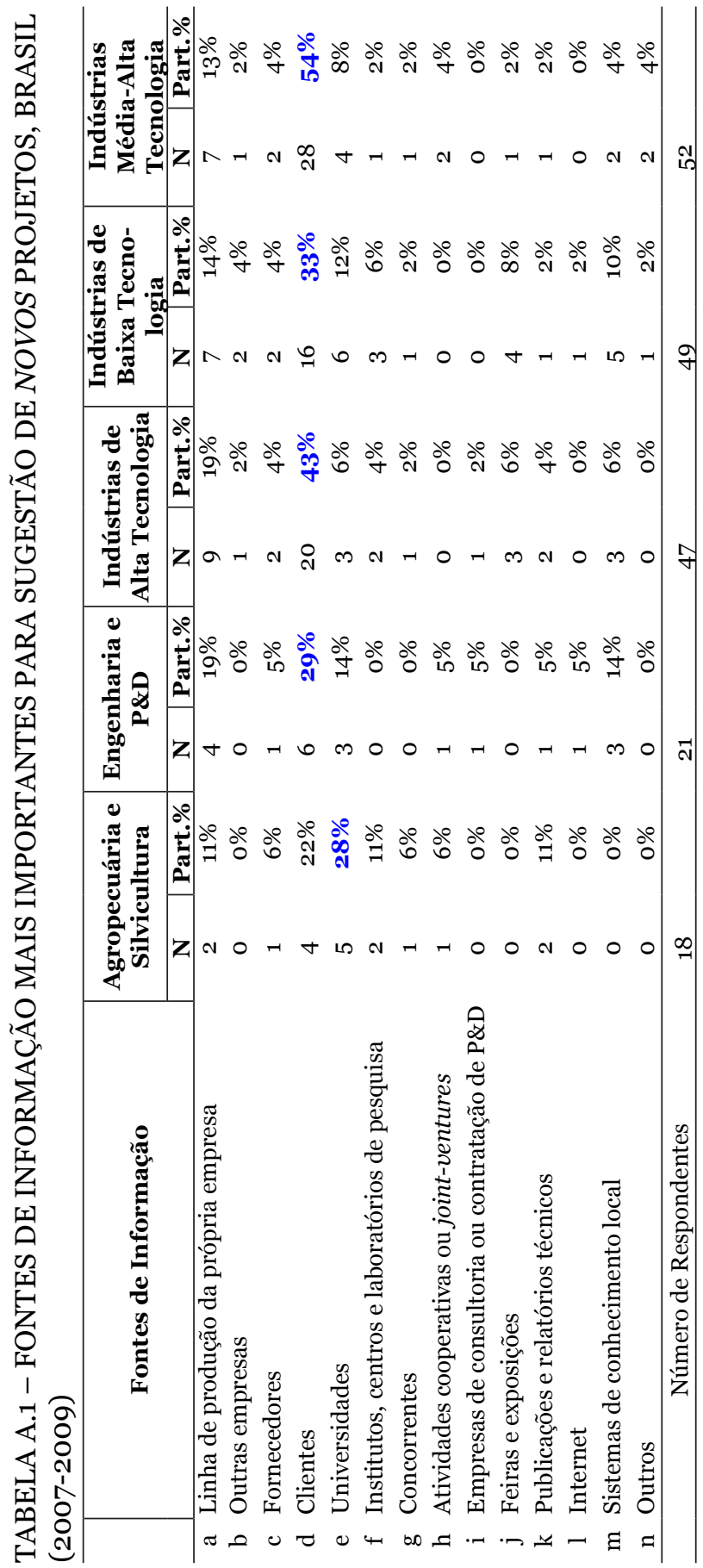


PINHO, M. A visão das empresas sobre as relações entre universidade...

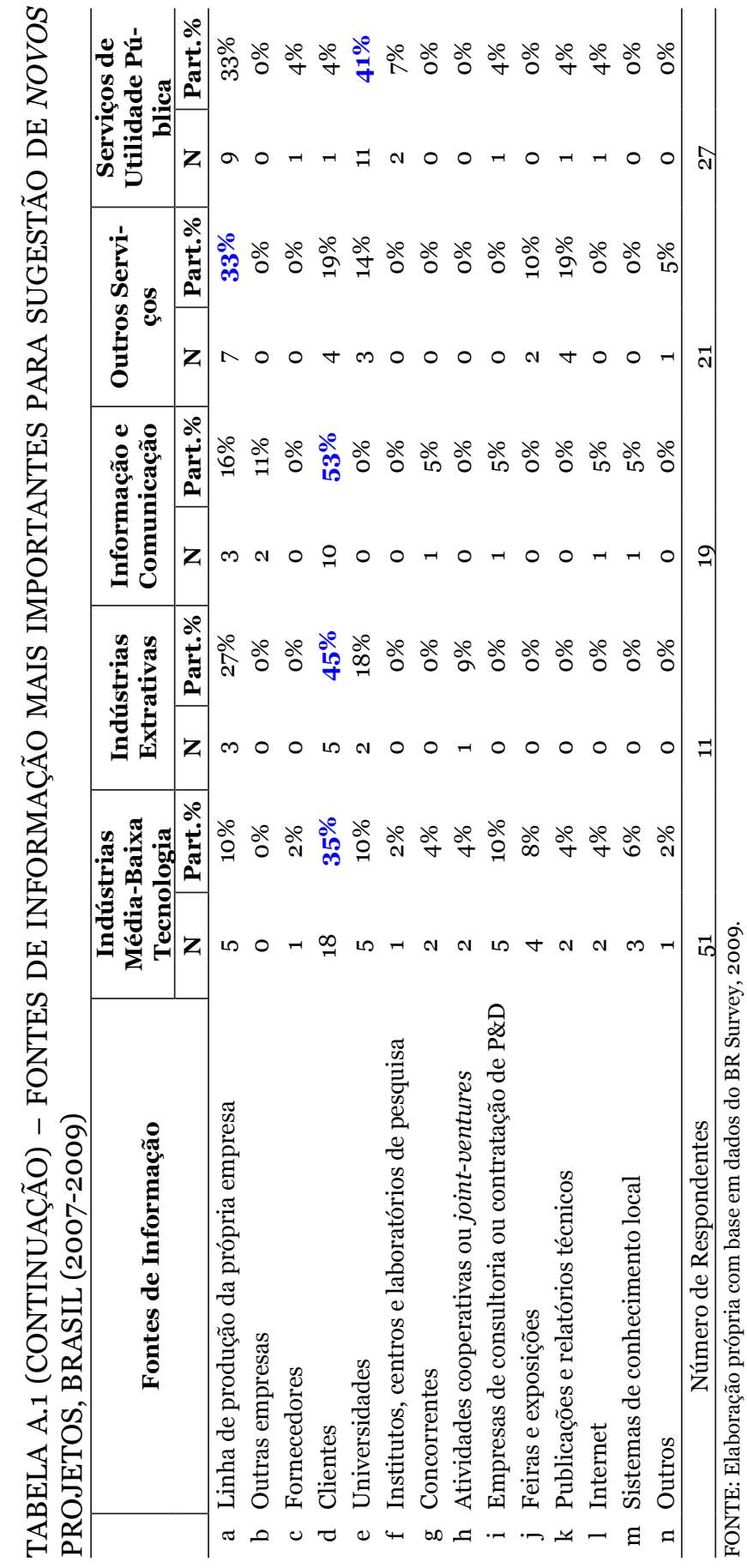


PINHO, M. A visão das empresas sobre as relações entre universidade...

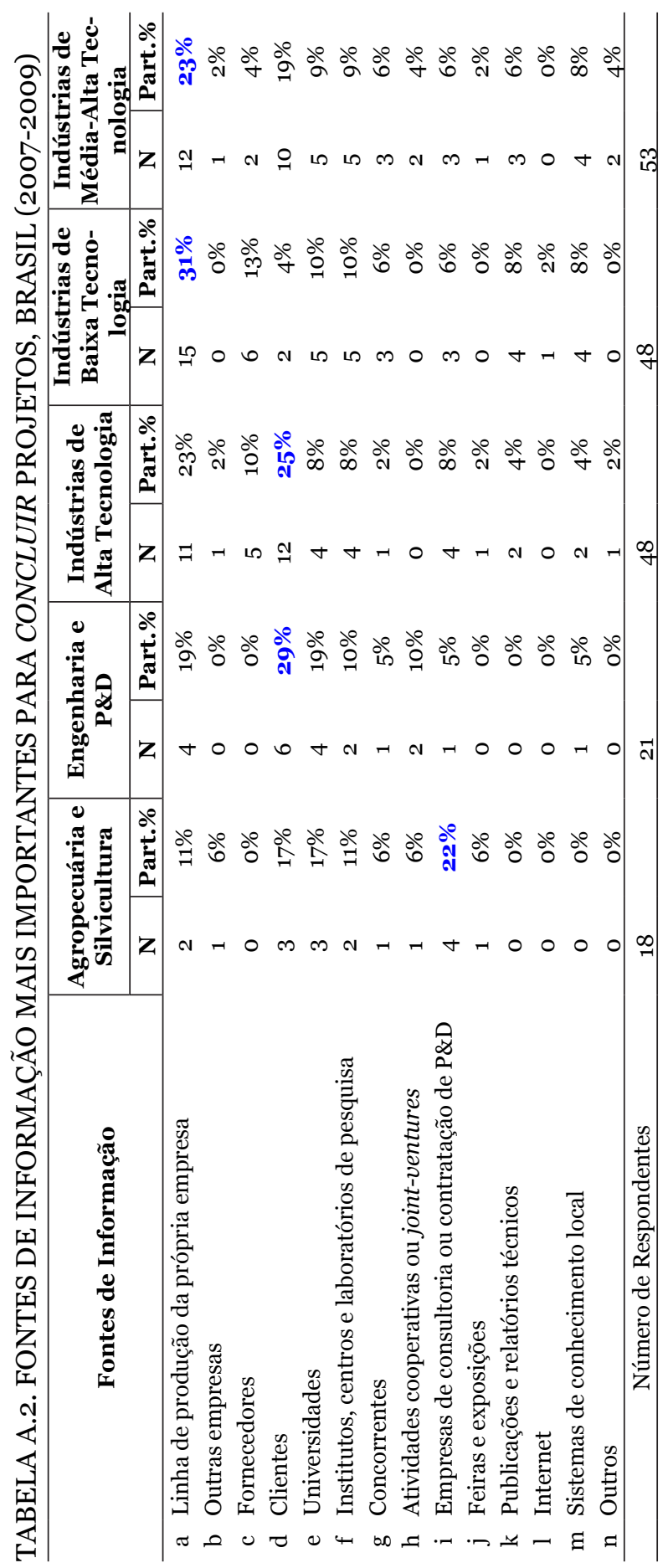


PINHO, M. A visão das empresas sobre as relações entre universidade...

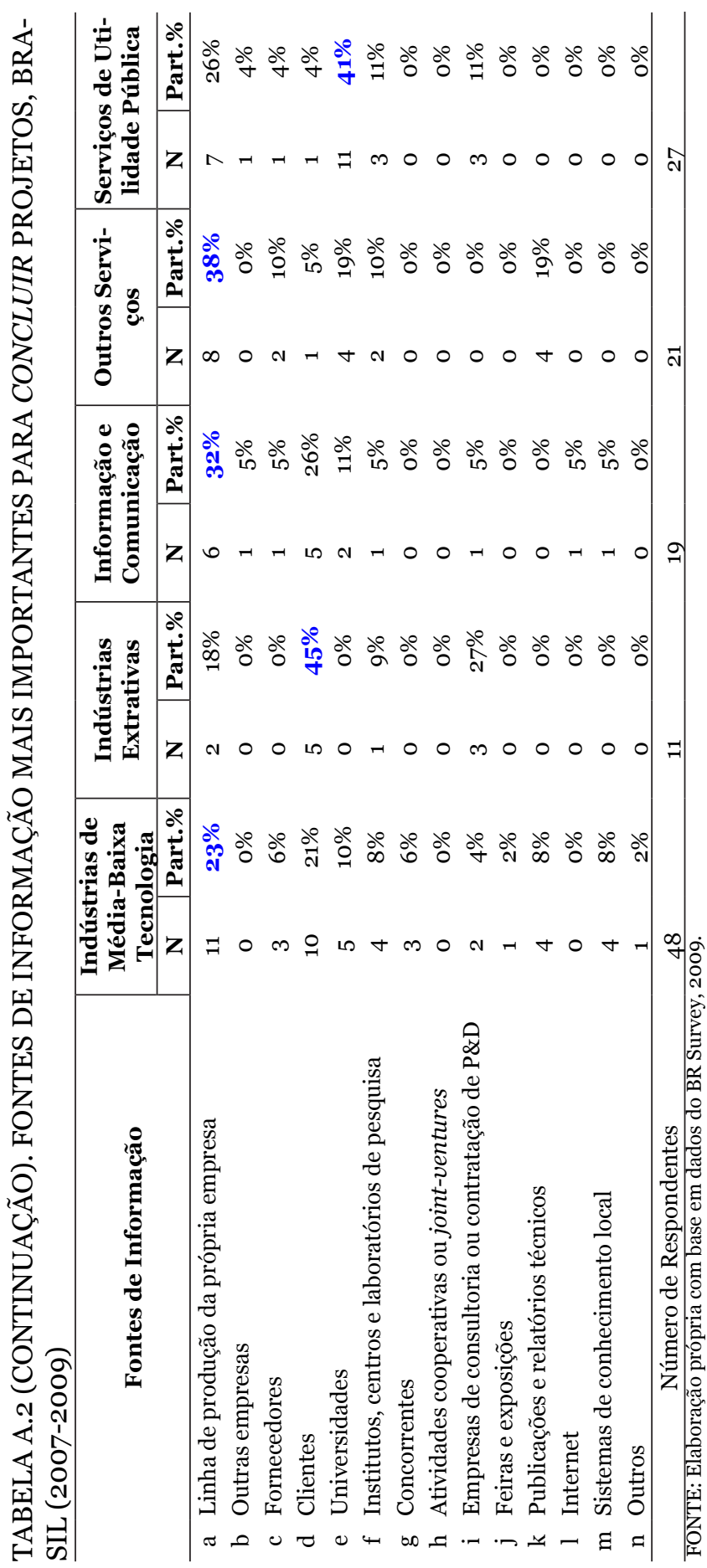


PINHO, M. A visão das empresas sobre as relações entre universidade...

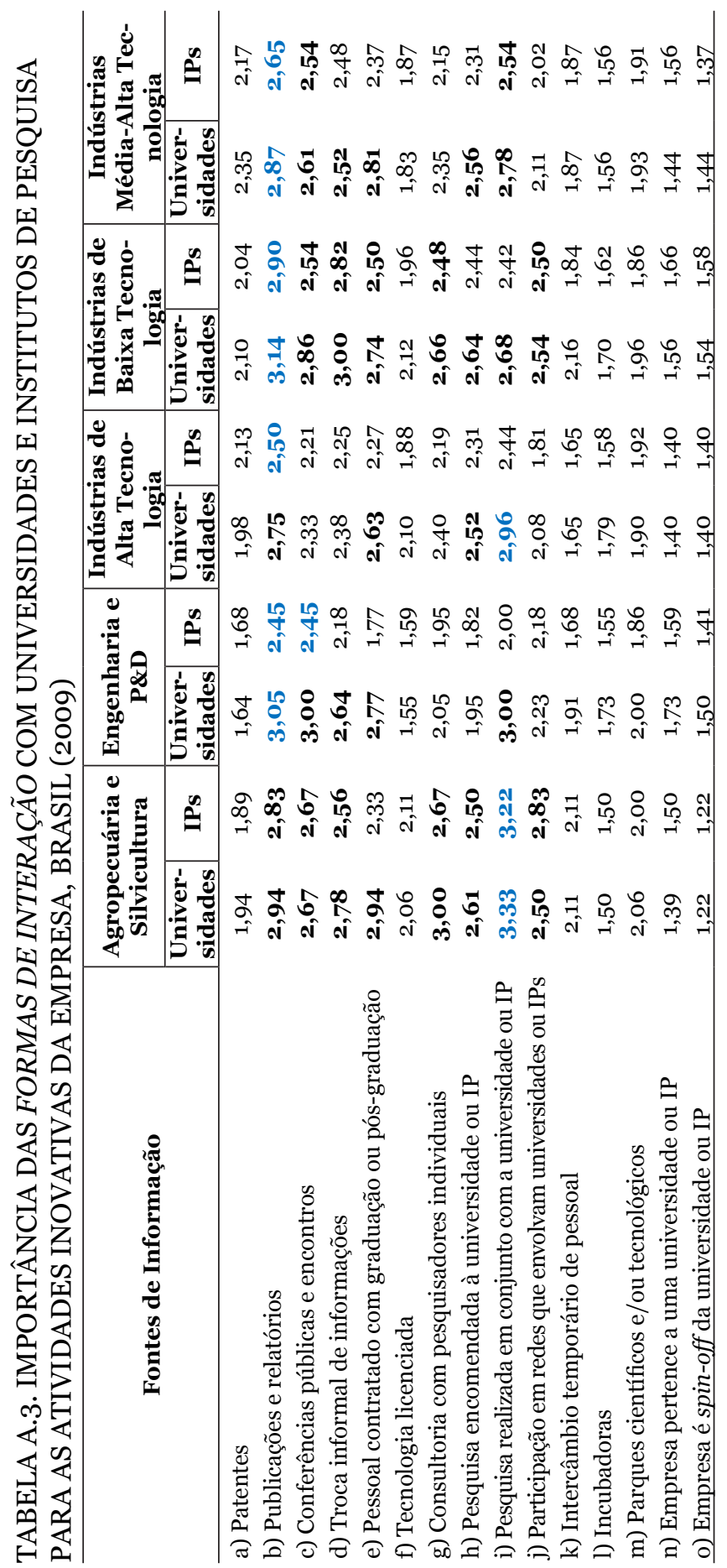


PINHO, M. A visão das empresas sobre as relações entre universidade...

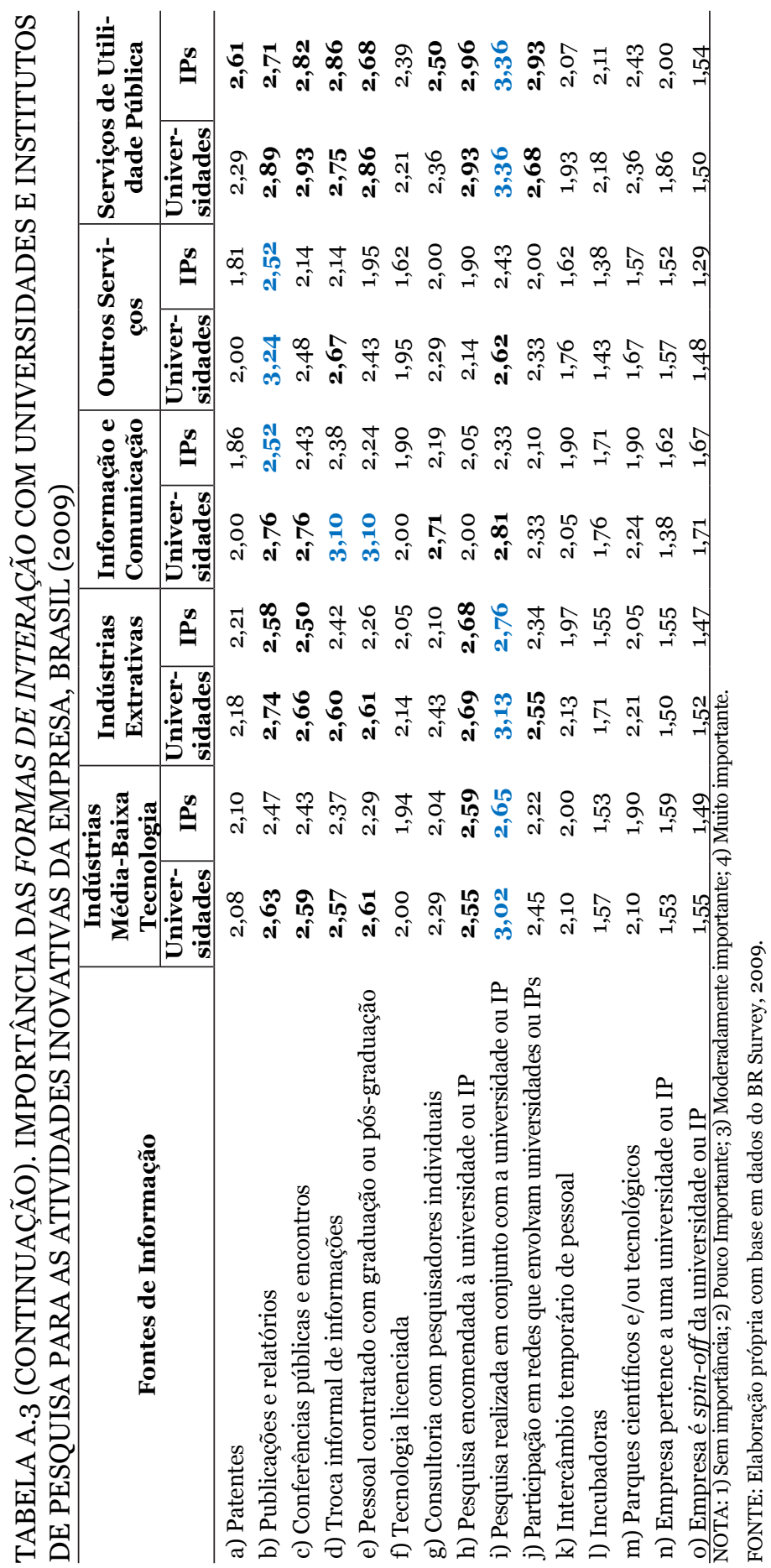


PINHO, M. A visão das empresas sobre as relações entre universidade...

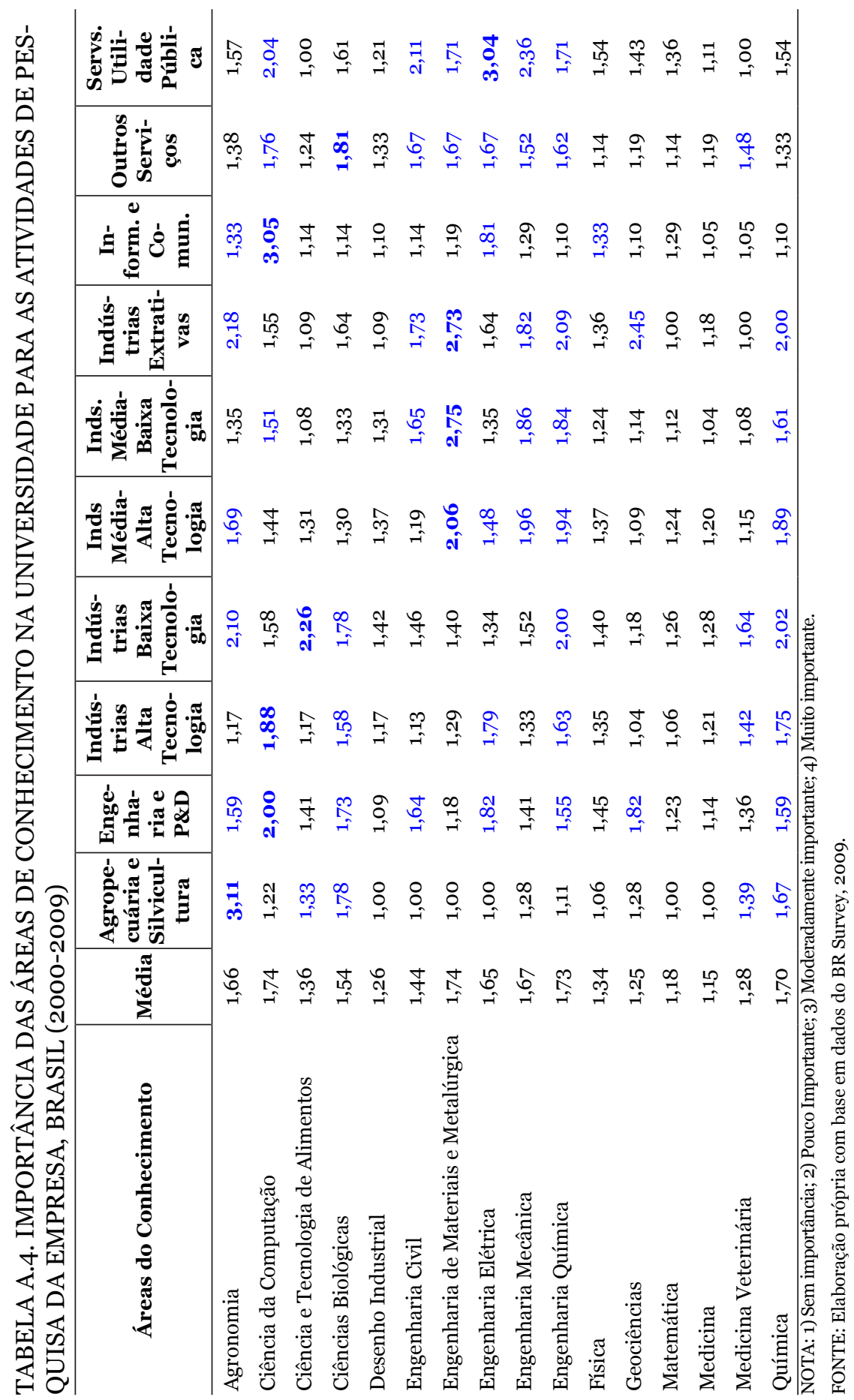


PINHO, M. A visão das empresas sobre as relações entre universidade...

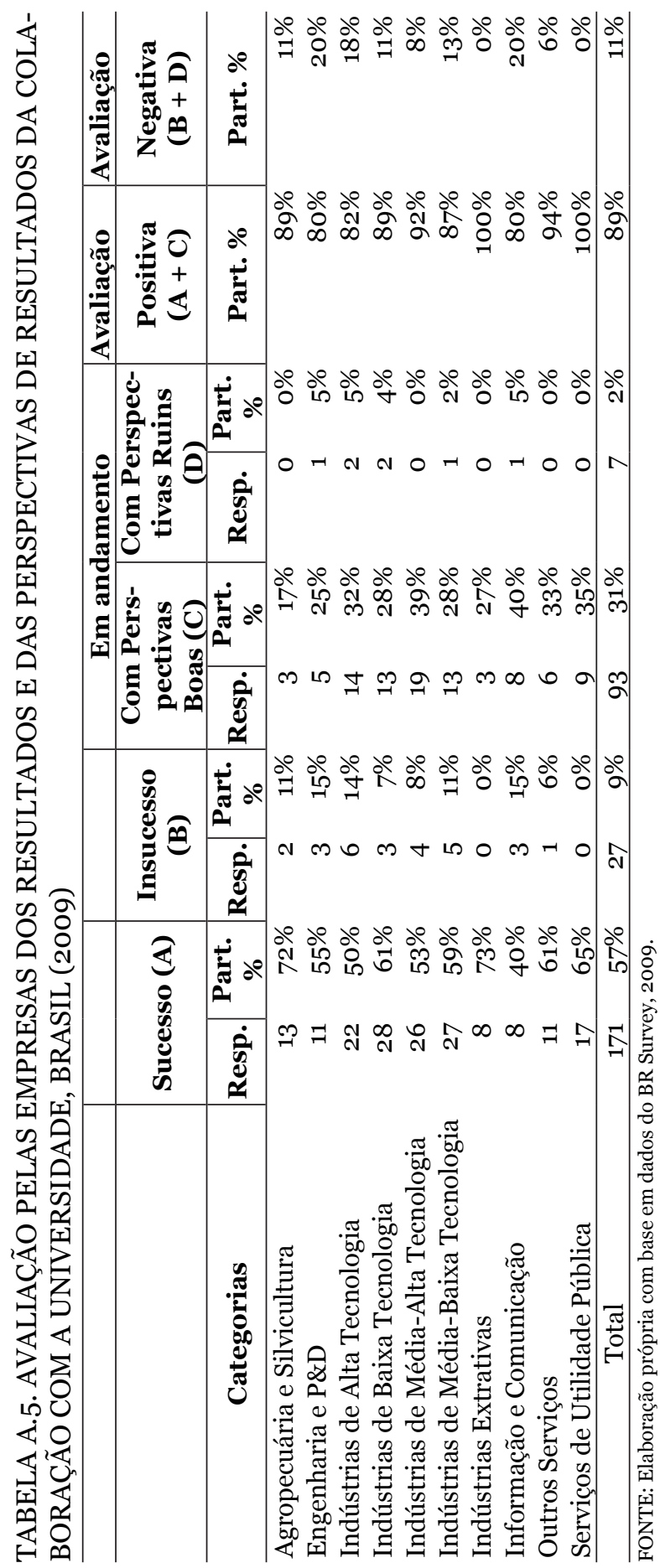

